\title{
The effect of replacing soybean oil with glycerol in feeding mixtures designed for utility layers on their production and state of health
}

\author{
Pavel Suchý, Eva Straková, Leo Kroupa and Ivan Herzig \\ Department of Nutrition, Animal Husbandry, and Animal Hygiene, Faculty of Veterinary Hygiene and Ecology, \\ University of Veterinary and Pharmaceutical Sciences Brno, Czech Republic
}

\begin{abstract}
The objective of this experiment was to replace soybean oil with glycerol in feeding mixtures for layers and assess its effect on performance, selected parameters of egg quality and health. Layers were divided into control (C) and experimental (E1, E2) groups of 24 layers each. The experiment was performed from week 20 until week 44 of layers' age. Soybean oil replacement with glycerol reached 50 and $100 \%$ in experimental feeding mixtures E1 and E2, as compared to the control. Oil replacement with glycerol in experimental groups resulted in a significant decrease $(P \leq 0.01)$ in weight of eggs, as compared to the control group - $C$ $(65.5 \pm 5.780 \mathrm{~g}), \mathrm{E} 1(64.53 \pm 4.640 \mathrm{~g})$ and E2 $(63.66 \pm 5.610 \mathrm{~g})$, and egg shell stability $\left(\mathrm{N} / \mathrm{cm}^{2}\right)-\mathrm{C}$ $33.79 \pm 6.557, E 131.96 \pm 6.995$ and E2 31.8 \pm 6.621 . The difference in the weight of egg shell between groups $C(7.13 \pm 0.687 \mathrm{~g})$ and E2 $(6.85 \pm 0.670 \mathrm{~g})$ was highly significant $(P \leq 0.01)$, the difference between $\mathrm{E} 1(7.00 \pm 0.820 \mathrm{~g})$ and $\mathrm{E} 2 \mathrm{groups}$ for the same parameter was significant $(P \leq 0.05)$. No significant differences were found between mean values of the weight of egg yolk and white. With regard to feed consumption, $50 \%$ replacement of oil with glycerol did not increase significantly the daily consumption of a feeding mixture per layer (1 egg) - C $122 \mathrm{~g}(132 \mathrm{~g})$ and E1 123g $(136 \mathrm{~g})$, as compared to $100 \%$ replacement in E2 $131 \mathrm{~g}(150 \mathrm{~g})$. The analysis of blood plasma after the prolonged continuous administration of glycerol in a feed did not show any negative effect on layers' health.
\end{abstract}

Keywords: glycerol, layers, production, egg quality, haematological and biochemical profile

\section{Introduction}

The use of glycerol in a diet for farm animals was first attempted and reported in the 1960s and 1970s. Some studies published in this period describe the use of glycerol in the nutrition of poultry and discuss the effect of glycerol on reproduction (Neville et al. 1970, Westfall \& Howarth 1976). The use of glycerol in diets designed for chickens is reported by Carew \& Foss (1974) and by Renner \& Elcombe (1964). Most authors have concluded that the optimum level of glycerol in a feeding mixture for broiler chickens is 5-10\% (Simon et al. 1996, Barteczko \& Kaminski 1999, Cerrate et al. 2006, Suchý et al. 2011). The level of $25 \%$ of glycerol was associated with pathological changes in different organs (crop, liver, kidneys) and had a negative effect on the performance of broiler chickens (Simon et al. 1997). The effect of raw glycerol in a diet on egg production, egg quality and the retention of nitrogen, calcium, 
phosphorus and metabolized energy was studied in layers aged 28-53 weeks by Swiatkiewicz \& Koreleski (2009). It was found that raw glycerol (obtained from the production of bio-oil) could be included in a diet of layers at a level of $6 \%$, without producing any negative effect on egg production, egg quality and the retention of nutrients and metabolized energy $\left(\mathrm{ME}_{\mathrm{d}}\right)$. The use of dietary glycerol in ruminants was studied by Adamski et al. (2011), its use in monogastric animals by Suchý et al. (2011). The use of glycerol in feeding mixtures will excite more attention with further developments in the production of bio-oil. The increasing production of bio-oil (methylester of rapeseed oil) will pose a problem of utilizing glycerol - the major side product of this technology. Since the production of glycerol exceeds its demand, further possibilities of its use are currently being explored. Animal production appears to be one of the perspective industries to use glycerol as a raw energy material in feeding mixtures for monogastric animals at relatively large amounts, ensuring the optimum way of its recycling, which is one of the goals of this study.

\section{Material and methods}

The experiment was performed with 72 Hisex Brown hybrid combination layers aged 17 weeks. Experimental monitoring (308 days) was started with 20-week-old layers. Layers were divided into three groups (control group C with 24 layers, experimental group E1 with 24 layers, and experimental group E2 with 24 layers) and reared in accordance with the technological rearing procedure. Layers were housed individually in a three-level cage technology with automatic watering, manual feeding (ad libitum) and the manual collection of eggs, in the accredited experimental enclosure of the Institute of Nutrition, Animal Husbandry, and Animal Hygiene, Faculty of Veterinary Hygiene and Ecology, University of Veterinary and Pharmaceutical Sciences in Brno, Czech Republic. Layers were fed with a complete feeding mixture in a mash form. The difference between experimental feeding mixtures (E1 and E2) and the control mixture was that 50 and $100 \%$ of soybean oil was replaced with glycerol. Glycerol used in this experiment was pure feeding glycerol containing $80 \%$ of glycerol in dry

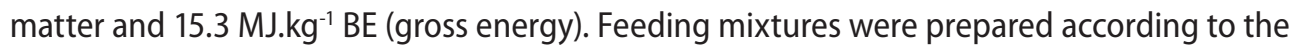
procedure described in Table 1.

Prior to comparative feeding experiments, all feeding mixtures were subjected to basic analysis in the laboratory of the Institute of Nutrition, Animal Husbandry, and Animal Hygiene, University of Veterinary and Pharmaceutical Sciences in Brno. Throughout the experiment, the live weight of individual layers was measured with an accuracy of $0.01 \mathrm{~kg}$, at the start of the experiment and in 28-day intervals. The consumption of a feeding mixture in a particular group was determined by weighing at an accuracy of $0.01 \mathrm{~kg}$. Daily feed consumption per layer was calculated; feed consumption per egg was determined from daily feed consumption and egg production. Eggs were collected every day at 7:00 a.m. followed by labelling and weighing at an accuracy of $0.01 \mathrm{~g}$. The number of laid eggs and the number of feeding days were used to calculate laying intensity. Egg quality was determined for a selected set of 24 eggs collected in each group during the experiment in 28-day intervals, i.e. a total of 264 eggs were analysed in each group. The following parameters in collected eggs were determined: weight, shell stability, yolk colour (using the Hoffman La Roche standard colour scale). Eggs were crushed to determine the weight of the egg shell, yolk and white at an accuracy of $0.01 \mathrm{~g}$. 
Table 1

Components contained in feeding mixtures, $\%$

\begin{tabular}{lrrr}
\hline Components & C & E1 & E2 \\
\hline Wheat & 33.00 & 32.00 & 31.00 \\
Maize & 30.00 & 30.00 & 30.00 \\
Soybean extracted meal & 24.00 & 24.00 & 24.00 \\
Methionine $100 \%$ & 0.20 & 0.20 & 0.20 \\
Monocalcium phosphate & 1.00 & 1.00 & 1.00 \\
Sodium chloride, NaCl & 0.30 & 0.30 & 0.30 \\
Limestone, ground & 9.30 & 9.30 & 9.30 \\
Soybean oil & 2.00 & 1.00 & 0.00 \\
Glycerol & 0.00 & 2.00 & 4.00 \\
Mikrop* & 0.20 & 0.20 & 0.20 \\
\hline
\end{tabular}

*The premix of specifically active substances used by the producer contained: vitamin A 1600000 IU, vitamin D3 $500000 \mathrm{IU}$, al pha-tocopherol $10000 \mathrm{mg}$, vitamin K3 300 mg, vitamin B1 800 mg, vitamin B2 1300 mg, vitamin B6600 mg, vitamin B12 $3 \mathrm{mg}$, biotin $30 \mathrm{mg}$, folic acid $500 \mathrm{mg}$, niacinamide $6000 \mathrm{mg}$, calcium pantothenate $2500 \mathrm{mg}$, betaine $50000 \mathrm{mg}$, butylhydroxytoluene $3400 \mathrm{mg}$, propyl gallate $1200 \mathrm{mg}$, ethoxyquin $540 \mathrm{mg}$, ferrous sulphate monohydrate $10000 \mathrm{mg}$, manganese oxide $16000 \mathrm{mg}$, zinc oxide $16000 \mathrm{mg}$, copper sulphate $1700 \mathrm{mg}$, potassium iodide $200 \mathrm{mg}$, sodium selenite $30 \mathrm{mg}$, cobalt sulphate $50 \mathrm{mg}$, phytase $50000 \mathrm{FTU}$, glucanase $24000 \mathrm{BGU}$, xylanase $1100000 \mathrm{EXU}$

Layers' health was examined on a daily basis. At the end of the experiment, 12 layers from each group were subjected to puncture of the vena basilica to collect blood samples for haematological and biochemical tests. Haematological tests were performed in native blood immediately after the collection of a blood sample, using established methods (Doubek et al. 2003). The following parameters were determined: red blood cell count (Er), white blood cell count (Le), the content of haemoglobin $(\mathrm{Hb})$ and haematocrit value ( $\mathrm{Hk}$ ). The values were used to calculate the mean haemoglobin corpuscular concentration (MCHC), mean corpuscular haemoglobin (MCH) and mean corpuscular volume (MCV).

Biochemical tests were performed with blood plasma, after centrifuging the samples of blood stabilized with heparin. The following biochemical parameters were determined: total protein (TP), glucose (GLU), cholesterol (CHOL), triacylglycerols (TAG), uric acid (UA), alkaline phosphatase (ALP), aspartate aminotransferase (AST), calcium (Ca), phosphorus (P), magnesium (Mg), sodium ( $\mathrm{Na})$, potassium $(\mathrm{K})$, chlorine $(\mathrm{Cl})$. Biochemical tests were performed in the Central Clinical Laboratory of the University of Veterinary and Pharmaceutical Sciences in Brno, using the Konelab 20i (Thermo Fisher Scientific, Waltham, MA, USA) analyser on the principle of photometric determination.

The results obtained were processed using mathematical and statistical methods implemented in UNISTAT for Excel 5.6 (Unistat Ltd, London, UK), using multiple comparison Tukey-HSD. Differences between the mean values were tested on two levels of significance $(P \leq 0.01$ and $P \leq 0.05)$.

\section{Results}

Generally, soybean oil replacement with glycerol in experimental feeding mixtures E1 and E2 (as compared to the control mixture $\mathrm{C}$ ) resulted in a decrease in the content of $\mathrm{N}$-substances, fat and starch, $\mathrm{Ca}, \mathrm{P}, \mathrm{BE}$ and $\mathrm{ME}_{\mathrm{d}^{\prime}}$ In contrast, the level of nitrogen-free extractives (NFE) increased. The increase was particularly remarkable in the feeding mixture E2 with the highest content of glycerol (Table 2). 
Table 2

Changes in the levels of nutrients $\left(\mathrm{g} \cdot \mathrm{kg}^{-1}\right)$ in feeding mixtures after replacing soybean oil with glycerol (experimental feeding mixtures E1 and E2), as compared to control (C)

\begin{tabular}{lrrrrr}
\hline Parameter & \multicolumn{1}{c}{$\mathrm{C}$} & \multicolumn{1}{c}{ E1 } & \multicolumn{1}{c}{$\Delta$} & \multicolumn{1}{c}{ E2 } & \multicolumn{1}{c}{$\Delta$} \\
\hline N-substances & 195.4 & 194.4 & -1.0 & 192.2 & -3.2 \\
Fat & 52.2 & 42.0 & -10.2 & 33.3 & -18.9 \\
Fibre & 17.0 & 18.1 & 1.1 & 21.8 & 4.8 \\
NFE & 583.9 & 593.4 & 9.5 & 603.0 & 19.1 \\
Starch & 433.3 & 422.8 & -10.5 & 413.8 & -20.5 \\
Ash & 151.5 & 150.0 & -1.5 & 149.7 & -1.8 \\
Calcium & 44.1 & 41.9 & -2.2 & 41.6 & -2.5 \\
Phosphorus & 6.5 & 6.0 & -0.5 & 5.9 & -0.6 \\
Magnesium & 2.3 & 2.4 & 0.1 & 2.5 & 0.2 \\
ME ${ }_{d^{\prime}}$ MJ & 11.1 & 10.8 & -0.3 & 10.8 & -0.3 \\
BE, MJ & 16.6 & 16.5 & -0.1 & 16.3 & -0.3 \\
NaCl & 2.9 & 3.5 & 0.6 & 3.9 & 1.0 \\
\hline
\end{tabular}

NFE: nitrogen-free extractive substances, $\mathrm{Me}_{\mathrm{d}}$ : metabolized energy, $\mathrm{BE}$ : gross energy, $\Delta$ : difference

The levels of most amino acids (AA) in experimental feeding mixtures decreased. Such changes were most significant in the feeding mixture E2 (Table 3). This also affected the total content of amino acids which decreased by $6.7 \mathrm{~g} \mathrm{~kg}^{-1}$ of feeding mixture in the group E1, and by $10.8 \mathrm{~g} \mathrm{~kg}^{-1}$ of feeding mixture in the group E2, as compared to the control (Table 3).

Table 3

Changes in the levels of amino acids $\left(\mathrm{g} \cdot \mathrm{kg}^{-1}\right)$ in experimental feeding mixtures E1 and E2 after replacing soybean oil with glycerol as compared to control $\mathrm{C}$

\begin{tabular}{lrrrrr}
\hline AA & C & E1 & $\Delta$ & E2 & \multicolumn{1}{c}{$\Delta$} \\
\hline Asp & 18.5 & 17.7 & -0.8 & 16.8 & -1.7 \\
Thre & 6.2 & 6.2 & 0.0 & 6.2 & 0.0 \\
Ser & 8.6 & 8.6 & 0.0 & 8.5 & -0.1 \\
Glu & 33.9 & 32.7 & -1.2 & 31.7 & -2.2 \\
Pro & 12.9 & 10.9 & 2.2 & 10.8 & -2.1 \\
Gly & 7.4 & 7.4 & 0.0 & 7.2 & -0.2 \\
Ala & 7.7 & 7.7 & 0.0 & 7.7 & 0.0 \\
Val & 8.4 & 8.5 & 0.1 & 8.4 & 0.0 \\
Met & 4.1 & 3.9 & -0.2 & 4.0 & -0.1 \\
Ile & 7.8 & 7.7 & -0.1 & 7.4 & -0.4 \\
Leu & 15.0 & 14.8 & -0.2 & 14.5 & -0.5 \\
Tyr & 6.0 & 5.9 & -0.1 & 5.7 & -0.3 \\
Phe & 9.6 & 8.7 & -0.9 & 8.7 & -0.9 \\
His & 5.2 & 5.2 & 0.0 & 5.0 & -0.2 \\
Lys & 9.7 & 9.0 & -0.7 & 8.8 & -0.9 \\
Arg & 14.4 & 13.8 & -0.6 & 13.2 & -1.2 \\
\hline
\end{tabular}

$\Delta$ : difference

Oil replacement with glycerol significantly decreased the content of fatty acids (FAs) in experimental feeding mixtures. Thus, feeding mixtures E1 and E2 showed a $21.4 \%$ and $43.1 \%$ decrease in the sum $\Sigma F A$, as compared to the control mixture. Most significant changes were found for linoleic, oleic/elaidic and palmitic acids. The levels of individual FAs together with the total sum of FAs are provided in Table 4. 
During the laying period, the mean live weight of layers gradually increased from $1.53 \pm 0.081 \mathrm{~kg}$ to $1.97 \pm 0.164 \mathrm{~kg}$ in the group $\mathrm{C}$, from $1.49 \pm 0.127 \mathrm{~kg}$ to $1.89 \pm 0.228$ in the group $\mathrm{E} 1$, and from $1.53 \pm 0.081 \mathrm{~kg}$ to $1.88 \pm 0.168 \mathrm{~kg}$ in the group E2. Differences between the mean values of the live weight of layers in individual groups during the laying period were not statistically significant although control layers showed the highest weight throughout the experiment; the weight of layers in the group E1 was lower than that of control layers; the lowest weight was found for layers in the group E2.

The mean daily consumption of a feeding mixture per layer and laid egg was evaluated during the laying period. The lowest mean daily consumption of a feeding mixture for the whole experimental period was found in control layers (122 g). The group E1 showed nearly the same consumption ( $123 \mathrm{~g}$ ) unlike the group E2 that showed the highest consumption (131 g). A similar trend was also confirmed in feed consumption per egg (132 g in C, $136 \mathrm{~g}$ in $\mathrm{E} 1$ and $150 \mathrm{~g}$ in $\mathrm{E} 2)$.

Table 4

Changes in the levels of FAs ( $\mathrm{g} .100 \mathrm{~g}^{-1}$ of fat) in experimental feeding mixtures E1 and E2 after replacing soybean oil with glycerol as compared to control C

\begin{tabular}{llrrrrr}
\hline FA & & \multicolumn{1}{c}{ C } & \multicolumn{1}{c}{ E1 } & \multicolumn{1}{c}{$\Delta, \%$} & E2 & \multicolumn{1}{c}{$\%$} \\
\hline C6:0 & Caproic acid & 0.009 & 0.011 & 16.22 & 0.011 & 16.95 \\
C8:0 & Caprylic acid & 0.002 & 0.004 & 81.03 & 0.002 & 11.64 \\
C10:0 & Capric acid & 0.004 & 0.007 & 70.98 & 0.002 & -52.16 \\
C12:0 & Lauric acid & 0.004 & 0.003 & -8.05 & 0.002 & -34.21 \\
C14:0 & Myristic acid & 0.037 & 0.031 & -16.14 & 0.021 & -44.29 \\
C16:0 & Palmitic acid & 5.335 & 4.412 & -17.30 & 3.304 & -38.07 \\
C16:1 & Palmitoleic acid & 0.054 & 0.046 & -14.85 & 0.320 & -41.16 \\
C17:0 & Heptadecanoic acid & 0.044 & 0.036 & -18.85 & 0.026 & -41.52 \\
C17:1 & cis-10-Heptadecanoic acid & 0.018 & 0.017 & -8.05 & 0.011 & -41.67 \\
C18:0 & Stearic acid & 1.562 & 1.100 & -29.62 & 0.646 & -58.65 \\
C18:1n9t+C18:1n9C & Oleic/elaidic acid & 12.434 & 9.750 & -21.58 & 7.225 & -41.89 \\
C18:2n6c+C18:2n6t & Linoleic acid & 26.665 & 20.981 & -21.32 & 15.426 & -42.15 \\
C18:3n3 & a-Linolenic acid & 2.265 & 1.604 & -29.16 & 0.866 & -61.77 \\
C20:0 & Arachidic acid & 0.174 & 0.129 & -29.06 & 0.099 & -43.30 \\
C20:1n9 & cis-11-Eicosenic acid & 0.171 & 0.097 & -43.09 & 0.091 & -46.71 \\
C20:2n6 & cis-11,14-Eicosadienoic acid & 0.017 & 0.015 & -9.48 & 0.013 & -20.26 \\
C22:0 & Behenic acid & 0.121 & 0.089 & -26.82 & 0.049 & -59.30 \\
C22:1n9 & Erucic acid & 0.012 & 0.012 & 0.00 & 0.006 & -47.30 \\
C23:0 & Tricosanoic acid & 0.020 & 0.013 & -33.98 & 0.012 & -41.11 \\
C24:0 & Lignoceric acid & 0.081 & 0.063 & -21.62 & 0.050 & -38.26 \\
I FA & & 49.029 & 38.420 & -21.64 & 27.893 & -43.11 \\
\hline
\end{tabular}

$\Delta$ : difference

The laying intensity was calculated from the total number of eggs laid for the whole experiment. The highest laying intensity for the whole experimental period was found in control layers (92.63\%), followed by a slightly lower value in the group E1 (90.08\%). The lowest laying intensity was found in the group E2 (87.49\%).

A total of 19.243 eggs were produced by layers during the whole experimental period (308 days). The group C produced 6741 eggs whereas groups E1 and E2 produced 6265 and 
6.237 eggs, respectively. The mean weight of eggs during the experiment was highest in the control group $(65.5 \pm 5.78 \mathrm{~g})$, which was statistically highly conclusive $(P \leq 0.01)$. A slightly lower weight of eggs was found in the group E1 $(64.53 \pm 4.64 \mathrm{~g})$ whereas the lowest weight was found in the group E2 $(63.66 \pm 5.61 \mathrm{~g})$.

Quality traits of eggs of selected parameters were determined in a set of eggs collected from 24 layers in each group in 28-day intervals, during the whole period of laying. The mean weight in the selected set of eggs during the whole experimental period was $65.21 \pm 5.76 \mathrm{~g}$ in the group C, $65.02 \pm 5.21 \mathrm{~g}$ in the group E1 and $64.36 \pm 6.433 \mathrm{~g}$ in the group E2.

The experiment also paid close attention to the selected parameters of egg quality. The mean value of egg shell stability $\left(\mathrm{N} / \mathrm{cm}^{2}\right)$ in a particular selected set of eggs during the whole experiment was $33.79 \pm 6.557$ in the group C, $31.96 \pm 6.995$ in the group E1 and $31.80 \pm 6.621$ in the group E2. Respective differences between the mean value in the group $C$ and those in groups E1 and E2 were statistically highly significant $(P \leq 0.01)$. The mean values of colour intensity for egg yolk (evaluated using the Hoffman La Roche standard colour scale) were $3.93 \pm 0.561$ in the group C, $3.90 \pm 0.590$ in the group E1 and $4.03 \pm 0.649$ in the group E2. A statistically significant difference $(P \leq 0.05)$ was only found between experimental groups $\mathrm{E} 1$ and E2. A summary of the results obtained for the whole experimental period indicates a statistically highly significant difference $(P \leq 0.01)$ in the mean value of egg shell weight between the group C $(7.13 \pm 0.687 \mathrm{~g})$ and the group E2 $(6.85 \pm 0.670 \mathrm{~g})$, and a statistically significant difference $(P \leq 0.05)$ in the mean value of egg shell weight between groups E1 $(7.00 \pm 0.82 \mathrm{~g})$ and E2. Mean values of egg yolk weight in individual groups of layers were $16.64 \pm 2.195,16.38 \pm 2.108$ and $16.56 \pm 2.538 \mathrm{~g}$ (groups C, E1 and E2), with no statistically significant differences being found between these mean values. Similarly, the mean values of egg white weight throughout the experimental period which were $41.43 \pm 3.964,41.63 \pm 3.526$ and $40.94 \pm 4.288 \mathrm{~g}$ (groups C, E1 and E2) showed no statistically significant differences.

Table 5

Results of haematological tests in layers from individual groups at the end of the experimental period $(x \pm S D, n=12)$

\begin{tabular}{|c|c|c|c|}
\hline Parameter & $C$ & E1 & E2 \\
\hline Er T..$^{-1}$ & $2.36 \pm 0.629$ & $2.42 \pm 0.555^{\mathrm{a}}$ & $1.87 \pm 0.413^{b}$ \\
\hline $\mathrm{Hk} 1.1^{-1}$ & $0.27 \pm 0.033$ & $0.25 \pm 0.027$ & $0.27 \pm 0.037$ \\
\hline $\mathrm{Hb} \mathrm{g.I^{-1 }}$ & $88.94 \pm 13.683$ & $88.64 \pm 20.133$ & $83.66 \pm 19.485$ \\
\hline $\mathrm{MCHC} \%$ & $33.63 \pm 3.722$ & $35.83 \pm 6.821$ & $31.54 \pm 5.594$ \\
\hline $\mathrm{MCH}$ pg & $39.42 \pm 9.685$ & $38.47 \pm 12.450$ & $47.76 \pm 18.863$ \\
\hline $\mathrm{MCV} \mathrm{fl}$ & $117.33 \pm 25.323$ & $106.48 \pm 24.236^{a}$ & $151.64 \pm 56.091^{b}$ \\
\hline Le G..$^{-1}$ & $12.92 \pm 3.110$ & $12.32 \pm 2.026$ & $14.46 \pm 2.311$ \\
\hline
\end{tabular}

${ }^{\text {ab } P \leq 0.05}$

In terms of the evaluation of health condition, no layers in the control group or experimental groups show any clinical signs of diseases during the experiment. At the end of the experiment, layers were subjected to haematological and biochemical tests using blood plasma samples. No statistically significant differences between groups were found in the mean values of individual haematological parameters (Table 5), except for the total red blood cell count where the mean value in the group E2 was statistically significantly lower $(P \leq 0.05)$ than that in the group E1. This was compensated by a statistically significant increase $(P \leq 0.05)$ 
in the mean corpuscular volume (MCV) as compared to group E1. The prolonged, continuous administration of glycerol in experimental feeding mixtures had no negative effect on biochemical parameters in layers (Table 6). No statistically significant differences were found between individual groups in the mean values of biochemical parameters.

Table 6

Results of biochemical tests performed with blood plasma collected from layers in individual groups at the end of the experimental period $(x \pm S D, n=12)$

\begin{tabular}{|c|c|c|c|}
\hline Parameter & C & E1 & E2 \\
\hline TP g..$^{-1}$ & $58.12 \pm 6.380$ & $56.51 \pm 5.395$ & $57.46 \pm 5.830$ \\
\hline GLU mmol. I $^{-1}$ & $12.56 \pm 0.758$ & $12.69 \pm 0.608$ & $12.14 \pm 0.981$ \\
\hline 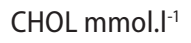 & $3.89 \pm 1.041$ & $3.12 \pm 1.003$ & $3.31 \pm 1.315$ \\
\hline TAG g..$^{-1}$ & $18.59 \pm 7.067$ & $13.38 \pm 7.669$ & $14.14 \pm 10.369$ \\
\hline UA mmol. $\mathrm{I}^{-1}$ & $180.0 \pm 46.478$ & $179.18 \pm 65.691$ & $170.58 \pm 45.845$ \\
\hline ALP $\mu$ kat..$^{-1}$ & $17.36 \pm 11.333$ & $10.89 \pm 9.746$ & $15.26 \pm 12.735$ \\
\hline AST $\mu$ kat..$^{-1}$ & $2.77 \pm 0.173$ & $2.68 \pm 0.360$ & $2.70 \pm 0.273$ \\
\hline Ca mmol..$^{-1}$ & $6.26 \pm 1.022$ & $5.82 \pm 1.114$ & $5.51 \pm 0.923$ \\
\hline P mmol..$^{-1}$ & $3.01 \pm 0.554$ & $2.99 \pm 0.473$ & $2.53 \pm 0.595$ \\
\hline Mg mmol..$^{-1}$ & $1.32 \pm 0.159$ & $1.27 \pm 0.147$ & $1.21 \pm 0.178$ \\
\hline Na mmol..$^{-1}$ & $153.41 \pm 2.103$ & $153.10 \pm 2.563$ & $152.83 \pm 2.176$ \\
\hline $\mathrm{K} \mathrm{mmol.}^{-1}$ & $4.06 \pm 0.197$ & $4.01 \pm 0.427$ & $3.92 \pm 0.262$ \\
\hline 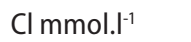 & $113.33 \pm 2.153$ & $114.08 \pm 2.051$ & $114.13 \pm 1.657$ \\
\hline
\end{tabular}

\section{Discussion}

The laboratory analysis of feed shows that 50 and $100 \%$ replacement of soybean oil with glycerol results in qualitative changes in the levels of nutrients in feeding mixtures (Table 2-4). The decreased content of nutrients in feeding mixtures containing glycerol was compensated by the increased intake of feeding mixture in layers in experimental groups, being reflected not only in feed consumption per layer, but also in feed consumption per egg. This was particularly remarkable in the group E2 where feed intake increased by $7.38 \%(0.131 \mathrm{~g})$, as compared to the control $(0.122 \mathrm{~g})$. It is assumed that lowered energy and nutrient values of experimental feeding mixtures resulted in a decrease in laying intensity in experimental groups during the experiment, namely to $90.08 \%$ in the group E1 and to $87.49 \%$ in the group E2, as compared to the control group (92.63\%); its course in all groups was in a good agreement with the results published by Halaj et al. (2002).

The decreased levels of energy and nutrients in experimental feeding mixtures for layers correlated with a highly significant decrease $(P \leq 0.01)$ in the mean weight of eggs in experimental groups of layers, as compared to control layers. Despite this decrease in egg weight, eggs from the experimental groups still show standard quality. This decrease in egg weight in experimental groups is likely to be due to a lowered content of MEd in experimental feeding mixtures, which is confirmed by Scott et al. (1982). The decreased weight of eggs can be associated not only with the lowered level of MEd but also with the decreased level of methionine (Kiiskinen 1987).

Soybean oil replacement with glycerol in experimental feeding mixtures particularly led to the decreased stability of egg shell in experimental groups. Despite changes in egg shell 
stability, one cannot draw an unambiguous conclusion that soybean oil replacement with glycerol had a negative effect on egg shell stability because the number of eggs with shell defects (cracked eggs, membraneous eggs) did not exceed $0.5 \%$ of the total number of eggs laid by layers in individual groups. The low percentage of eggs with damaged shell is far below the values reported in operational conditions. In contrast to literature data (Simeonovová et al. 1995), shell stability for eggs in control and experimental groups is of a standard level. The colour of egg yolk differed in its mean values between groups only minimally. The increased values of yolk colour intensity in experimental group E2 can be explained in terms of reduced egg production and decreased egg weight. As a result, more pigment could be deposited in the egg yolk, as compared to the control group C or the experimental group E1. The values of egg yolk colour measured in this study are generally lower than the mean value (5.23) reported by Yildiz et al. (2006).

The weight of egg shell was non-significantly lower in groups E1 and E2 in the course of the experimental period. The difference between the mean value in the control group and that in the group E1 was statistically significant $(P \leq 0.05)$ whereas the difference between the mean value in the control group and that of $\mathrm{E} 2$ was highly significant $(P \leq 0.01)$.

It follows from the results of the analysis of the weight of egg yolk and egg white that no statistically conclusive differences were found between respective groups. It can be concluded that soybean oil replacement with glycerol had no effect on the weight of egg yolk and egg white. The mean weight of egg yolk in eggs analysed in our experiment was slightly lower than that reported by Halaj et al. (1998) or Máchal et al. (2004). The mean weight of egg white determined in our experiment corresponds with the values reported by Tůmová \& Ebeid (2005). During the experimental period, control and experimental layers did not show any clinical symptoms of any disease. Haematological and biochemical tests performed with the samples of blood plasma from layers did not confirm a negative effect of soybean oil replacement with glycerol on the layers' health in experimental groups. The results of haematological tests are in a good agreement with the values reported for layers by Straková et al. $(2007,2008)$ and Suchý et al. (2004). The values of biochemical parameters in blood plasma fell in physiological ranges, being in a good agreement with the values determined in clinically healthy layers by Straková et al. $(2007,2008)$.

In conclusion, the results of this study show that it is possible to replace $50 \%$ of soybean oil with glycerol that serves as the major energy source of feeding mixtures intended for utility layers, without any significant effects on egg production and quality. A higher degree of substitution, for example $100 \%$ substitution of oil with glycerol is not suitable due to the insufficient levels of some nutrients, particularly essential FAs. However, with this level of substitution one has to consider the nutrient and energy requirements of layers. It is particularly necessary to know the composition and energy value of used glycerol since feeding glycerol currently available on the market with feeding commodities may differ in quality.

\section{Acknowledgement}

Financial support from the Ministry of Education, Youth, and Sports of the Czech Republic (Grant No MSMT 6215712402) is gratefully acknowledged. 


\section{References}

Adamski M, Kupczyński R, Chladek G, Falta D (2011) Influence of propylene glycol and glycerin in Simmental cows in periparturient period on milk yield and metabolic changes. Arch Tierz 54, 238-248

Barteczko J, Kaminski J (1999) The effect of glycerol and vegetable fat on some physiological indices of the blood and excess of fat in broiler carcasses. Ann Warsaw Agric Univ Anim Sci 36, 197-209 [in Polish]

Carew LB, Foss DC (1974) Glycerol in diet of chicks. Poult Sci 53, 1907

Cerrate S, Yan F, Wang Z, Coto, C, Sacakli P, Waldroup PW (2006) Evaluation of glycerine from biodiesel production as a feed ingredient for broilers. Int J Poult Sci 5, 1001-1007

Doubek J, Bouda J, Doubek M, Furll M, Knotková Z, Pejřilová S, Pravda D, Scheer P, Svobodová Z, Vodička R (2003) [Veterinary Hematology. First issue], Noviko, Brno, Czech Republic [in Czech]

Halaj M, Benková J, Baumgartner J (1998) [Parameters of hen egg quality in various breeds]. Czech J Anim Sci 43, 375-378 [in Czech]

Halaj M, Halaj P, Roháček B, Arpášová H (2002) [Productive performance and egg quality of laying hens in postmoulting production cycles]. Slov Chov 12, 43-49 [in Czech]

Kiiskinen T (1987) Effects of restricted methionine end energy intake on egg weight and shell quality. Agricult F Sci Finl 8, 513-521

Máchal L, Jeřábek S, Straková E (2004) [Defective eggs and their relationship to egg yield, egg and body weight in hens of five original laying lines]. Czech J Anim Sci 49, 51-57 [in Czech]

Neville WJ, Macphers JW, King GJ (1970) The contraceptive action of glycerol in gilts. J Anim Sci 31, 227

Renner R, Elcombe A (1964) Factors affecting utilization of »carbohydrate-free« diets by nutrition. 2. Level of glycerol. J Nutr 84, 327-330

Scott ML, Nesheim MC, Zouny RJ (1982) Nutrition of the Chicken. 3rd ed. Cornell University, Ithaca, New York, NY, USA

Simeonovová J, Kalová J, Vysloužil J, Jeřábek S (1995) [Evaluation of strength and nondestructive deformation of eggs in hens of Rhode-Island-White and White-Leghorn breeds by prototypes of electronic-instruments]. Živoč Vyr 40, 269-272 [in Czech]

Simon A, Bergner H, Schwabe M (1996) Glycerol-feed ingredient for broiler chickens. Archiv Anim Nutr 49, 103-112

Simon A, Schwabe M, Bergner H (1997) Glycerol supplementation to broiler rations with low crude protein content. Archiv Anim Nutr 50, 271-282

Straková E, Suchý P, Šugerková M, Macháček M (2007) [Positive effect of plant-based diet on the performance and health of laying hens]. Acta Vet Brno 76, 31-37 [in Czech]

Straková E, Suchý P, Herzig I, Šerman V, Mas N (2008) [The long-term administration of clinoptilolitesupplemented feed to layers and its effect on performance, haematological parameters and metabolic profile]. Czech J Anim Sci 53, 212-216 [in Czech]

Suchý P, Straková E, Jarka B, Thiemel J, Večerek V (2004) [Differences between metabolic profiles of egg-type and meat-type hybrid hens]. Czech J Anim Sci 49, 323-328 [in Czech]

Suchý P, Straková E, Kroupa L, Herzig I (2011) Pure and raw glycerol in the diet of broiler chickens, its effect on the production parameters and slaughter value. Arch Tierz 54, 308-318

Swiatkiewicz S, Koreleski J (2009) Effect of crude glycerin level in the diet of laying hens on egg performance and nutrient utilization. Poult Sci 88, 615-619

Tůmová E, Ebeid T (2005) Effect of time of oviposition on egg quality characteristics in cages and in a litter housing system. Czech J Anim Sci 50, 129-134

Westfall FD, Howarth B (1976) Effect of time of glycerol deposition on fertility of chickens. Poult Sci 55, 21052106 
Yildiz G, Zacykli P, Gungor T (2006) The effect of dietary Jerusalem artichoke (Helianthus tuberosus) on performance, egg quality characteristics and egg cholesterol content in laying hens. Czech J Anim Sci 51, 349-354

Received 19 September 2011, accepted 23 November 2011.

Corresponding author:

Pavel Suchý

email: suchyp@vfu.cz

University of Veterinary and Pharmaceutical Science Brno, Palackého 1/3, 61242 Brno, Czech Republic 